\title{
Maternity waiting homes and traditional midwives in rural Liberia
}

\section{Jody R. Lori ${ }^{\text {a,*, }}$, Michelle L. Munro ${ }^{\text {b }}$, Sarah Rominski ${ }^{\text {c }}$, Garfee Williams ${ }^{\text {d,e }}$, Bernice T. Dahn ${ }^{\text {e }}$, Carol J. Boyd ${ }^{\text {b }}$, Jennifer E. Moore ${ }^{\mathrm{f}}$, Walter Gwenegale ${ }^{\mathrm{e}}$}

a Division of Health Promotion and Risk Reduction, School of Nursing, University of Michigan, Ann Arbor, USA

b School of Nursing, University of Michigan, Ann Arbor, USA

c Global REACH, University of Michigan Medical School, Ann Arbor, USA

d Phebe Hospital, School of Nursing, Suakoko, Liberia

e Liberia Ministry of Health and Social Welfare, Monrovia, Liberia

${ }^{\mathrm{f}}$ Agency for Healthcare Research and Quality, Rockville, USA

\section{A R T I C L E I N F O}

\section{Article history:}

Received 5 February 2013

Received in revised form 23 May 2013

Accepted 7 August 2013

\section{Keywords:}

Liberia

Maternal mortality

Maternity waiting homes

Midwifery

\begin{abstract}
A B S T R A C T
Objective: Maternity waiting homes (MWHs) can reduce maternal morbidity and mortality by increasing access to skilled birth attendants (SBAs). The present analysis was conducted to determine whether MWHs increase the use of SBAs at rural primary health clinics in Liberia; to determine whether traditional midwives (TMs) are able to work with SBAs as a team and to describe the perceptions of TMs as they engage with SBAs; and to determine whether MWHs decrease maternal and child morbidity and mortality. Methods: The present analysis was conducted halfway through a large cohort study in which 5 Liberian communities received the intervention (establishment of an MWH) and 5 Liberian communities did not (control group). Focus groups were conducted to examine the views of TMs on their integration into health teams. Results: Communities with MWHs experienced a significant increase in team births from baseline to post-intervention $(10.8 \%$ versus $95.2 \%, P<0.001)$, with greater TM engagement. Lower rates of maternal and perinatal death were reported from communities with MWHs. Conclusion: The reduction in morbidity and mortality indicates that the establishment of MWHs is an effective strategy to increase the use of SBAs, improve the collaboration between SBAs and TMs, and improve maternal and neonatal health.
\end{abstract}

(C) 2013 International Federation of Gynecology and Obstetrics. Published by Elsevier Ireland Ltd. All rights reserved.

\section{Introduction}

Access to quality healthcare is a basic human right that is often unavailable in low-income countries. Lack of access to quality health care has resulted in high rates of maternal and perinatal mortality, with more than 287000 maternal deaths [1] and 5.65 million perinatal deaths [2] reported worldwide annually.

Two Millennium Development Goals are aimed at reducing neonatal mortality and improving maternal health [3]; however, a barrier to meeting these goals is that many skill-based and goal-directed interventions fail at creating empowered environments where providers and patients work as partners, taking responsibility for their actions. Fundamental to creating an empowered environment is the need to include communities in negotiations for the types of services offered and to understand how they view their inclusion in the healthcare system [4]. To be successful, an intervention must include all healthcare providers, involve community members, provide a referral system, and strengthen links between the healthcare delivery system and the

\footnotetext{
* Corresponding author at: Division of Health Promotion and Risk Reduction, University of Michigan, School of Nursing, 400 N. Ingalls, Room 3352, Ann Arbor, MI 48 109, USA Tel.: + 173476 30097; fax: + 17346470351

E-mail address: jrlori@umich.edu (J.R. Lori).
}

communities to overcome the barriers that prevent access to intrapartum care with a skilled birth attendant (SBA) [5-7].

Although countries are encouraged to develop and implement plans to ensure access to SBAs, there has been increased recognition of the important cultural role of traditional birth attendants in maternity care [5,6]. Traditional midwives (TM), in coordination with SBAs, can identify problems during prenatal, childbirth, and postpartum periods and, when necessary, refer women to skilled providers. For this reason and to make better use of human resources, the WHO encourages the inclusion of TMs in healthcare teams [5].

Liberia is a low-resource country working to meet the healthcare needs of its population; its maternal mortality ratio (990/100 000 pregnancies) and its perinatal mortality rate (38/1000 pregnancies) are among the highest in the world [5,8]. Although the Ministry of Health and Social Welfare has made strides to provide an integrated program of maternal, neonatal, and child health services, critical barriers often keep women from accessing these services [9]. Less than half (47\%) of all births in Liberia are attended by a health professional [10]. As in many other settings, TMs have been filling this gap.

The present study draws on data from a larger study that was aimed at increasing access to skilled maternal, neonatal, and child health services through the deployment and evaluation of maternity waiting homes (MWHs). The purpose of the present study was to determine 
whether MWHs increase the use of SBAs at rural primary health clinics in Liberia; to determine whether TMs are able to work with SBAs as a team and to describe the perceptions of TMs as they engage with SBAs; and to determine whether MWHs decrease maternal and child morbidity and mortality. The primary outcome was the effectiveness of MWHs in increasing the use of SBAs and decreasing maternal and child morbidity and mortality. The secondary outcomes included an examination of the changing role of TMs. The findings presented here mark the halfway point of a 4-year study.

\section{Material and methods}

Poverty often restricts and even excludes people from participating in healthcare decisions [4]. To address this issue, the present study used a participatory action research model, based on the concepts of community mobilization, capacity building at the local level, and enhancement of self-reliance and sustainability. Key elements of community mobilization were used to develop a model for engagement at each level of the research process [11] (Fig. 1).

The study used a cohort design and included 10 rural primary healthcare facilities, 5 with an MWH that was constructed during the study (exposed intervention group or MWH group) and 5 without an MWH (unexposed comparison group or non-MWH group). In all facilities, the SBA was a certified midwife. The 5 clinics in the MWH group were matched by size, location, distance from a paved road, and population demographics to the 5 clinics unaffiliated with an MWH. All 10 clinics provide standard services including basic emergency obstetric and neonatal care, and referral services according Liberia's Rebuilding Basic Health Services program.

The 10 communities are based in Bong County, a rural county located in north central Liberia with a population of 333481 . Bong County experienced some of the heaviest fighting and destruction during the civil war, leaving its health system decimated. The catchment population in the present study was 78446 with approximately 18043 women of childbearing age.

Prior to construction of the MWHs, the communities pledged the provision of raw materials and services (making bricks, hauling sand and gravel, cutting wood) and the donation of food and cooked meals for the construction teams. The communities agreed that each $\mathrm{MWH}$ would be run by a core group of TMs elected by the Community Health Development Committee and overseen by the SBA at the respective clinic. These groups were established by the Ministry of Health and Social Welfare and charged with decision-making in terms of clinic management and provision of community health services under the National Policy and Strategy for Community Health [12]. The Community Health Development Committees decided that management of the MWHs by TMs would lend credibility among the communities. At each MWH, a TM Council was elected and charged with responsibility for the day-to-day operation of the MWH. The TM Council also made community members, TMs, and pregnant women aware of the MWHs.

The MWHs were available free of charge to all pregnant women served by the rural primary health clinics, and access was neither dependent on referral nor on the distance between a woman's home and the clinic. Traditional midwives and family members were encouraged to accompany women to the MWHs. Women also had the opportunity to stay at an MWH when extended prenatal or postnatal care was required. Each MWH had a minimum of 8 beds with mosquito netting, an outdoor kitchen with cooking utensils, a sheltered area for firewood, and outdoor toilet facilities. There was a general meeting room for TMs and families to conduct business or gather together for social events.

Institutional review board approval was obtained from the Health Sciences and Behavioral Sciences Institutional Review Board of the

\section{A MODEL FOR IMPROVED MATERNAL, NEONATAL, AND CHILD HEALTH}

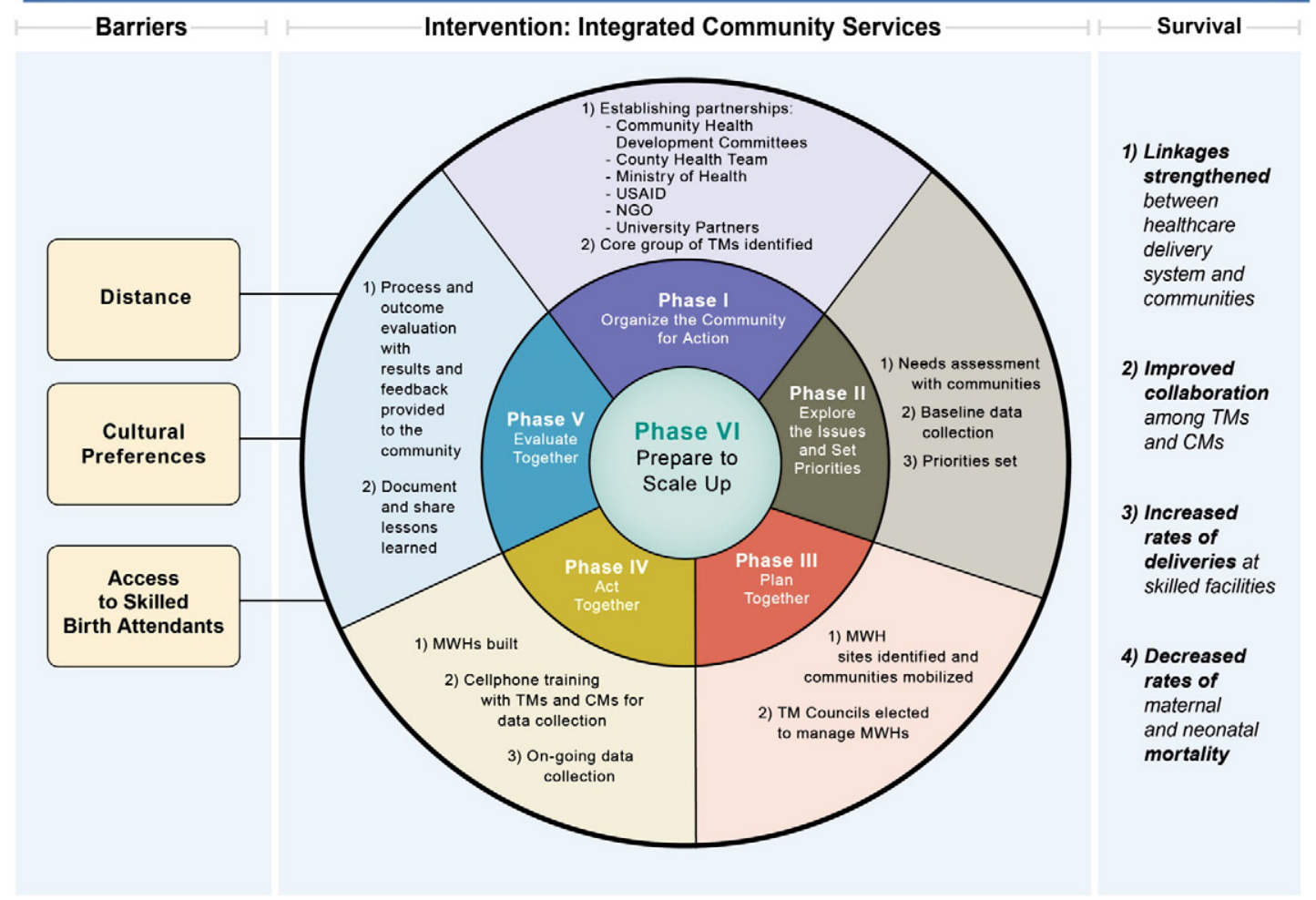

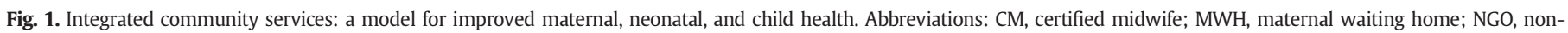
governmental organization; TM, traditional midwife; USAID, US Agency for International Development. 
University of Michigan, Ann Arbor, MI, USA, and the study was cleared by the Liberian Ministry of Health and Social Welfare and the County Health Officer directly responsible for oversight of the facilities involved.

Quantitative data on the frequency of MWH use, the number of referrals, the presence of an SBA at delivery, the proportion of team births (a birth attended by both a TM and SBA), and perinatal and maternal outcomes were collected from logbooks that had been completed by the certified midwives following each delivery. Qualitative data were obtained through in-depth focus group discussions with TMs ( $n=46$ ) from the communities served by the rural healthcare facilities with MWHs. Only TMs from sites with functioning MWHs were included as participants. All focus groups and interviews were audio-recorded and transcribed verbatim. Interviews were conducted in Kpelle or English by a research-trained, female Liberian nurse fluent in both languages. To reduce bias, the research team developed open-ended questions. The participants were asked similar questions from multiple angles. Prior to the collection of qualitative data, the purpose of the interview was explained to each participant, confidentiality was assured, and verbal informed consent was obtained.

The proportion of team births compared with non-team births was assessed using a logistic regression model with generalized estimating equations to evaluate differences from baseline (December 1 , 2010 to February 28, 2011) to the post-intervention period (June 1 to August 31, 2012) in the MWH and non-MWH communities, while controlling for clustering within communities. The numbers of perinatal and maternal death were reported for the period from March 1, 2011, through September 30,2012, and the analyses were completed while controlling for the estimated number of women at childbearing age in each community. The data were recorded, coded, and analyzed using SPSS 20.0 (IBM, Armonk, NY, USA). $P<0.05$ was considered statistically significant.

The focus group data were reviewed by 4 members of the research team in an iterative process to develop constructs of meanings and themes and to derive patterns from the data. A broad inductive process of condensing raw text data, establishing links within the data, and developing key themes was used to analyze the qualitative data. Validity was ensured with the use of methodologic and analytic documentation [13], and throughout the analysis numerous discussions occurred to verify interpretations and ideas.

\section{Results}

At the time of the present analysis, 500 pregnant women had stayed at an MWH with an average length of stay of 3 days (range, 1-33 days) (Table 1).

The proportion of team births increased over time both in communities with an MWH and in those without; however, the increase did not reach statistical significance in the non-MWH group (Wald $\chi^{2}=3.75$, degree of freedom (df) $=1, P=0.053$ ) (Fig. 2).
Additionally, lower rates of maternal and perinatal death were reported from communities with an MWH compared with those without an MWH, but the difference between the 2 groups reached statistical significance for maternal death only (Wald $\chi^{2}=4.22, \mathrm{df}=1$, $P=0.040$ ) (Fig. 3).

Select demographics of the focus group participants are shown in Table 2. The TMs shared their implicit knowledge of perceptions within the community and discussed changes to their own identity as birth attendants. Two primary themes emerged from the data: linking communities with facilities; and safe delivery.

The improved linking of communities with facilities was supported by 2 broad conceptual categories: "no more hiding" and encouragement at the community level for women to access skilled care at delivery. The concept of "no more hiding" was used to describe the actions of pregnant women as well as those of TMs. Previous research [10] in the communities included in the study identified secrecy surrounding pregnancy and childbirth as a major barrier to accessing skilled care. The TMs in the focus groups considered the MWHs to be helpful and useful to the community and to themselves. Several TMs noted that they were happy to bring women to the MWH so they could rest before giving birth. According to the participants, husbands also encouraged their wives to use an MWH.

The second theme identified from the data was that of safe delivery. The conceptual categories supporting this theme included reduction in the burden felt by TMs and provision of a safe place for delivery. Many TMs openly discussed the burden they felt before construction of the MWHs. When accompanying a pregnant woman to a clinic in the past, they often worried about their own safety because there was no space at the clinic for TMs to stay. The increased collaboration between certified midwives and TMs was identified as a contributing factor to lifting this burden from the TMs. The TMs also felt confident that the clinic staff would take care of the pregnant women.

According to the TMs, the MWHs provided a safe environment for pregnant women preparing for delivery, which is in contrast to the traditional birth experience of rural Liberian women, who are often alone during delivery with minimal support [10]. The TMs consistently described MWHs as a safe space to await delivery where the women did not have to worry about supplies, work, or health (their own and that of their infant).

\section{Discussion}

Maternal waiting homes seem to be an attractive option for women at the end of pregnancy, leading to an increase in the number of births attended by SBAs. Most importantly, communities with an MWH reported lower rates of maternal and perinatal death than communities without an $\mathrm{MWH}$.

A strong cultural preference for TMs still exists in Liberia [14] with TMs currently serving as the main providers of health care during pregnancy and childbirth at the community level. The involvement of TMs

Table 1

Maternity waiting home characteristics.

\begin{tabular}{|c|c|c|c|c|c|c|}
\hline Community & $\begin{array}{l}\text { Catchment } \\
\text { population }^{\mathrm{a}}\end{array}$ & MWH opened & MWH cost & $\begin{array}{l}\text { Number of facility-based } \\
\text { deliveries since MWH } \\
\text { construction }\end{array}$ & $\begin{array}{l}\text { MWH stays since } \\
\text { MWH construction }^{\mathrm{b}, \mathrm{c}}\end{array}$ & $\begin{array}{l}\text { Duration of } \\
\text { MWH stay, } \mathrm{d}^{\mathrm{d}}\end{array}$ \\
\hline Yila & 2998 & March 5, 2011 & $\$ 6,500$ & 237 & $239(100.0)$ & $3.3(1-33)$ \\
\hline Zebay & 3552 & May 13, 2011 & $\$ 9,500$ & 198 & $100(50.5)$ & $2.0(1-7)$ \\
\hline Janyea & 4035 & January 26, 2012 & $\$ 8,500$ & 123 & $105(85.4)$ & $4.5(1-31)$ \\
\hline Bellemu & 3617 & March 8, 2012 & $\$ 8,000$ & 63 & $56(88.9)$ & $2.2(1-6)$ \\
\hline Salala ${ }^{\mathrm{e}}$ & 22637 & Not open & $\$ 25,000$ & - & - & - \\
\hline
\end{tabular}

Abbreviation: MWH, maternity waiting home.

a Data provided by the Ministry of Health, Bong County Health Team.

b Values are given as number (percentage of all facility-based deliveries).

c The number of MWH stays may be greater than the number of facility-based deliveries because some patients used MWHs for prenatal stays only

d Values are given as mean (range).

e As of November 1, 2012, the MWH in Salala had not been opened because it was still awaiting furniture. 


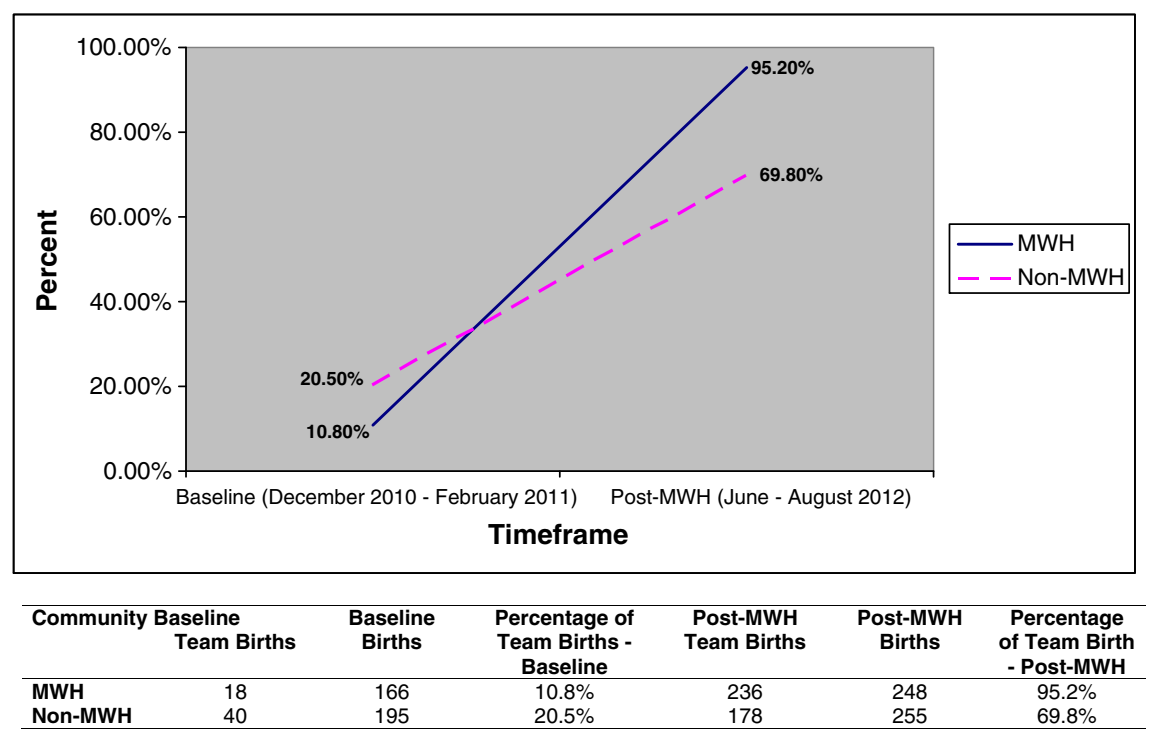

Fig. 2. Proportion of team births before and after the construction of maternal waiting homes.

with MWHs and the associated maternal, neonatal, and child health activities will recast and solidify the role of TMs as birth supporters and community health promoters. The MWHs are viewed positively by TMs and seem to draw TMs and SBAs together, as evidenced by the increase in team births. Through the TMs, women in the communities were informed and encouraged to make use of the MWHs. By involving community members and TMs in the planning and construction of MWHs, the innovative approach described in the present study addresses barriers to accessing skilled intrapartum care noted in the literature, including lack of knowledge about the existence of an MWH [15], location [16], cost [17], and cultural barriers [18].

There was a notable increase in the number of team births performed by SBAs and TMs at both MWH and non-MWH sites from baseline to post-intervention. This overall increase reflects the strategy taken by Liberia's Ministry of Health and Social Welfare to rebuild the health system. Significant efforts have been made to integrate and coordinate services with community involvement and participation.

The present findings have several strengths including a diversity of evaluation perspectives. The clinics were matched in terms of population demographics, size, and location. The study also included mixed methods of data collection using results from qualitative interviews (inductive data) as well as quantitative findings (deductive data). The employment of both methods to answer complex questions results in detailed information on outcome measures and provides more contextual data through the voices of participants. Given the complexity of developing strategies to increase access to essential and emergency obstetric care, this approach provides a more complete understanding of the impact and use of MWHs.

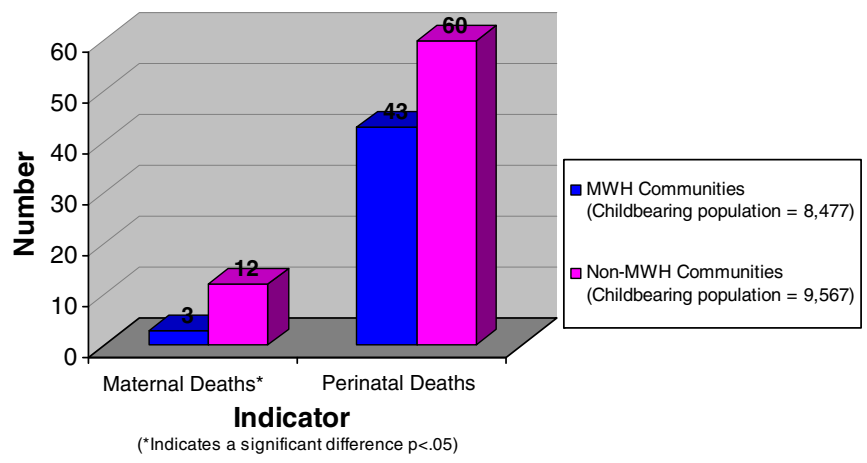

Fig. 3. Health indicators by comparison groups (March 2011 to September 2012).
Although MWHs, run by TMs at sites close to rural healthcare facilities that are staffed by SBAs, hold great potential, the present study also has limitations. The MWH facilities opened at different points in time, and thus each location required the analysis of team births during a 3month baseline time period before construction of the $\mathrm{MWH}$, followed by an analysis of team births during a 3-month time period after all MWHs had opened. The non-MWH communities started with a larger proportion of team births at baseline, which may be related to a better initial relationship between TMs and SBAs or may be an artifact of record keeping. Given the unpredictability of deliveries, it is difficult to conclude whether the trends noted after 2 years will be sustained over time. Another limitation is the lack of randomization in assigning communities to receive an MWH. Owing to the constraints within the terms of the grant, the MWHs could only be built on pre-existing foundations, introducing the potential for bias. Finally, the present intervention and its evaluation are ongoing and thus the results are not final.

The sustainability of MWHs as an intervention to decrease the barrier of distance for women living in remote, rural areas of Liberia who require access to safe delivery depends on support from multiple levels. At the top level, the present data have contributed to the inclusion of MWHs as a key component in Liberia's accelerated action plan to reduce maternal and neonatal morbidity and mortality [19]. Communities have made a commitment to ownership and upkeep of the MWH structures, but this will need further evaluation as homes begin to require structural maintenance. Future experimental research is needed to examine

Table 2

Demographic characteristics of traditional midwives $(n=46){ }^{\text {a }}$

\begin{tabular}{lc}
\hline Parameter & Value \\
\hline Age, $\mathrm{y}^{\mathrm{b}}$ & $44(40-56)$ \\
Marital status & $29(63.0)$ \\
$\quad$ Married & $3(6.5)$ \\
$\quad$ Never married & $2(4.4)$ \\
$\quad$ Divorced & $12(26.1)$ \\
$\quad$ Widowed & $7.5(5-11)$ \\
Number of children & $5.5(3-8)$ \\
Number of living children & \\
Formal schooling & $33(71.7)$ \\
$\quad$ None & $8(17.4)$ \\
2nd-6th grade & $5(10.9)$ \\
$\quad$ 7th-12th grade & $15(7-22)$ \\
Traditional midwife experience, y & \\
\hline a Values are given as median (interquartile range) or number (percentage). \\
b Statistics were computed only on those who knew their age (n = 27).
\end{tabular}


whether MWHs can indeed bridge the gap to access skilled obstetric care in rural areas.

At the time of writing, a comprehensive program of obstetric services, including the provision of MWHs, is being developed in Liberia to increase the number of facility-based deliveries. The present results indicate that the establishment of stronger links with communities and TMs as integral partners in the healthcare system helps to accelerate the reduction of maternal and newborn mortality in Liberia.

\section{Acknowledgments}

The present study and the development of this article were supported in part by a research grant from the US Agency for International Development, Grant USAID-M-OOA-GH-HSR-10-40 (J.R.L. and C.J.B., co-principal investigators) and $1 \mathrm{~K} 01$ TW00 8763-01A1 from the Fogarty International Center at the National Institutes of Health (J.R.L., principal investigator). Support to M.L.M. and J.E.M. was provided by the National Institutes of Health, National Institutes for Nursing Research grant numbers F31NR01 2852 and F31NR01 2855, respectively. The views expressed in this article are those of the authors and do not necessarily reflect the position or policy of the US Department of Health and Human Services or the Agency for Healthcare Research and Quality.

\section{Conflict of interest}

The authors have no conflicts of interest.

\section{References}

[1] World Health Organization, UNICEF, UNFPA, The World Bank. Trends in maternal mortality: 1990 to 2010. http://www.unfpa.org/webdav/site/global/shared/documents/ publications/2012/Trends_in_maternal_mortality_A4-1.pdf. Published 2012. Accessed November 21, 2012.

[2] Lawn JE, Blencowe H, Pattinson R, Cousens S, Kumar R, Ibiebele I, et al. Stillbirths: Where? When? Why? How to make the data count? Lancet 2011:377(9775):1448-63.

[3] United Nations. We Can End Poverty 2015: Millennium Development Goals. http://www.un.org/millenniumgoals/. Accessed November 21, 2012.

[4] Macfarlane S, Racelis M, Muli-Musiime F. Public health in developing countries. Lancet 2000;356(9232):841-6.
[5] World Health Organization. Working with Individuals, Families and Communities to Improve Maternal and Newborn Health. http://whqlibdoc.who.int/hq/2010/WHO_ MPS_09.04_eng.pdf. Published 2010. Accessed November 21, 2012.

[6] Byrne A, Morgan A. How the integration of traditional birth attendants with formal health systems can increase skilled birth attendance. Int J Gynecol Obstet 2011;115(2):127-34

[7] Campbell OM, Graham WJ. Lancet Maternal Survival Series steering group. Strategies for reducing maternal mortality: getting on with what works. Lancet 2006;368(9543): 1284-99.

[8] Global Health Workforce Alliance. 2011 Africa Human Resources for Health Scorecard Incorporating Skilled Health Personnel, Maternal Mortality, Reproductive Health and Female Life Expectancy at Birth. http://www.who.int/workforcealliance/media/news/ 2012/2012AfricaHRHScorecard.pdf. Accessed November 21, 2012.

[9] Africare-Liberia. Liberia's Child Survival Project - Concept Note. Washington DC: Africare; 2010.

[10] Liberia Institute of Statistics and Geo-Information Services, Ministry of Health and Social Welfare, National AIDS Control Program, Macro International Inc. Liberia Demographic and Health Survey 2007. http://www.measuredhs.com/pubs/pdf/FR201/ FR201.pdf. Published June 2008. Accessed November 21, 2012.

[11] Howard-Grabman L. Demystifying Community Mobilization: An Effective Strategy to Improve Maternal and Newborn Health. http://www.accesstohealth.org/toolres/ pdfs/ACCESS_DemystCM.pdf. Published 2007. Accessed November 21, 2012.

[12] Ministry of Health and Social Welfare. National Strategy and Policy for Community Health Services. https://docs.google.com/viewer?a=v\&q=cache:TYoCzxp3k7AJ: www.basics.org/documents/National-Strategy-and-Policy-for-Community-HealthServices_Liberia.pdf + Policy + and + Strategy + for + Community + Health + Liberia\& $\mathrm{hl}=\mathrm{en} \& \mathrm{gl}=\mathrm{us} \& \mathrm{pid}=\mathrm{bl} \& \mathrm{srcid}=$ ADGEESjR6NmdAYsA-QWDWqqk70ZNzANJsXbcF34 mLhy8gxjvXLwllsksrvUxvyOtovqQ-eurQ6624N2ntqQaidgUXGcMEUC2K6K2Xea5Qa6 HrX9Tpil_mgqdmTPHLqRQj_ppgqhkkJF1\&sig=AHIEtbS_lyGR0lZixdTng4918dIRIgAzA. Published October 2008. Accessed November 21, 2012.

[13] Sandelowski M, Barroso J. Writing the proposal for a qualitative research methodology project. Qual Health Res 2003;13(6):781-820.

[14] UNICEF. UNICEF Annual Report for Liberia. http://www.unicef.org/about/annual report/files/Liberia_COAR_2010.pdf. Published 2010. Accessed May 6, 2013.

[15] Mramba L, Nassir FA, Ondieki C, Kimanga D. Reasons for low utilization of a maternity waiting home in rural Kenya. Int J Gynecol Obstet 2010;108(2):152-3.

[16] Wilson JB, Collison AH, Richardson D, Kwofie G, Senah KA, Tinkorang EK. The maternity waiting home concept: the Nsawam, Ghana experience. The Accra PMM Team. Int J Gynecol Obstet 1997;59(Suppl. 2):S165-72.

[17] van Lonkhuijzen L, Stekelenburg J, van Roosmalen J. Maternity waiting facilities for improving maternal and neonatal outcome in low-resource countries. Cochrane Database Syst Rev 2012;10:CD006759.

[18] Eckermann E, Deodato G. Maternity waiting homes in Southern Lao PDR: the unique 'silk home'. J Obstet Gynaecol Res 2008;34(5):767-75.

[19] Ministry of Health and Social Welfare, World Health Organization. Road Map for Accelerating the Reduction of Maternal and Newborn Morbidity and Mortality in Liberia. Published 2007. 